\title{
Efficient Gold(I) Acyclic Diaminocarbenes for the Synthesis of Propargylamines and Indolizines
}

\author{
Mélanie Aliaga-Lavrijsen, ${ }^{\dagger}$ Raquel P. Herrera, ${ }^{*}{ }^{\ddagger}$. M. Dolores Villacampa, ${ }^{\dagger}$ \\ and M. Concepción Gimeno* ${ }^{*} \dagger$ \\ ${ }^{\dagger}$ Departamento de Química Inorgánica, Instituto de Síntesis Química y Catálisis Homogénea (ISQCH), and ${ }^{\ddagger}$ Departamento de \\ Química Orgánica, Laboratorio de Organocatálisis Asimétrica, Instituto de Síntesis Química y Catálisis Homogénea (ISQCH), \\ CSIC-Universidad de Zaragoza, C/ Pedro Cerbuna, No. 12, E-50009 Zaragoza, Spain
}

\section{Supporting Information}

ABSTRACT: Mononuclear gold(I) acyclic diaminocarbenes (ADCs) were prepared by the reaction of 1,2-cyclohexanediamine with the corresponding isocyanide complexes [AuCl$(\mathrm{CNR})]\left(\mathrm{R}=\mathrm{Cy},{ }^{t} \mathrm{Bu}\right)$. The three-component coupling of aldehydes, amines, and alkynes was investigated by using these gold(I) ADC complexes. The new gold(I) metal complexes are highly efficient catalysts for the synthesis of propargylamines and indolizines in the absence of solvent and in mild conditions. This method affords the corresponding final products with excellent yields in short reaction times. Additionally, chiral gold(I) complexes with ADCs have been prepared and tried in the enantioselective synthesis of propargylamines.

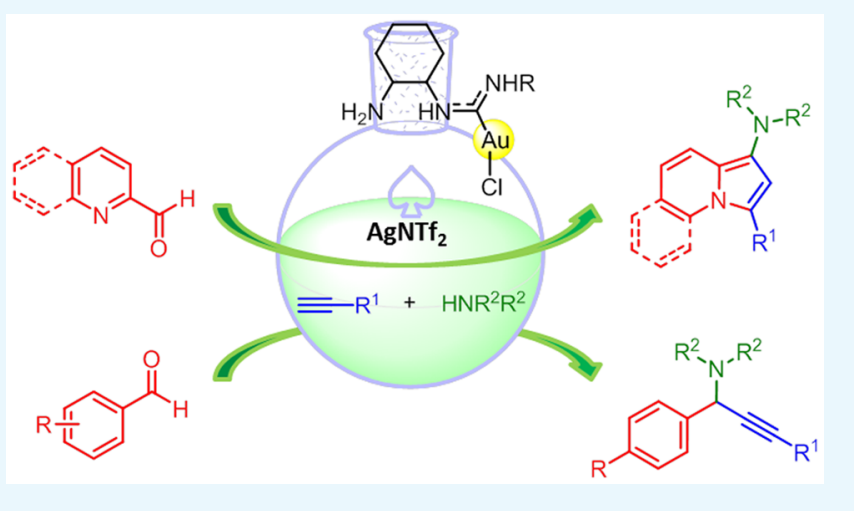

discovery. ${ }^{34,35}$ Among these processes, the formation of propargylamines via a three-component coupling procedure, commonly called $\mathrm{A}^{3}$-coupling reaction, is an interesting approach center of continuous investigations. ${ }^{36-40}$ Propargylamines are versatile building blocks for the synthesis of nitrogen-containing molecules. The structural core of the resulting amine derivatives is present in many natural products and drug candidates (Figure 1). ${ }^{41-45}$ Some examples such as pargyline, ${ }^{46}$ rasagyline, ${ }^{47}$ and selegiline ${ }^{48}$ have found applications in the treatment of neurodegenerative diseases, such as Parkinson's and Alzheimer's diseases. ${ }^{4,50}$

Therefore, the development of a new synthetic procedure to obtain propargylamines is a very attractive aim because they are useful intermediates. Interestingly, the use of gold-based catalysts in these $\mathrm{A}^{3}$-coupling procedures has been shortly explored. $^{51-61}$

The synthesis of indolizines in a tandem reaction involving an MC approach is also an interesting active goal. ${ }^{62,63}$ Indolizines, one of the most important $N$-fused heterocyclic skeletons, are found in a variety of biological active compounds (Figure 1). Indolizines display a broad spectrum of potential pharmacological activities and are used in a variety of applications for drug discovery. ${ }^{64}$

Gold-based catalysts have been scarcely used for the preparation of indolizines. ${ }^{65-70}$ It is worth mentioning that

Received: June 15, 2018

Accepted: August 9, 2018

Published: August 23, 2018 

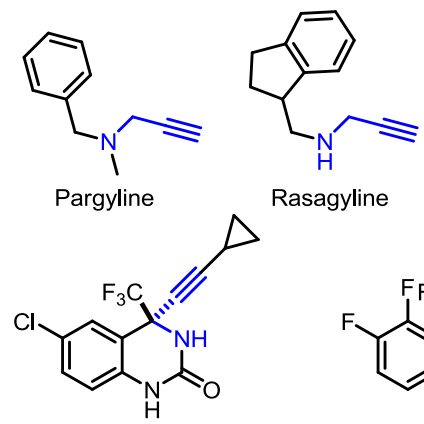

DPC 961 second-generation NNRTI

Rasagyline

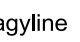

Selegiline

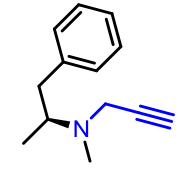

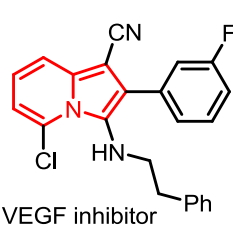

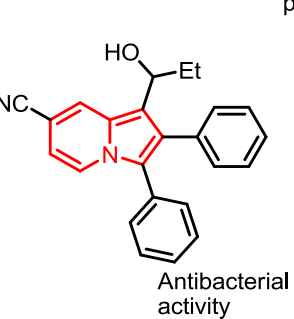

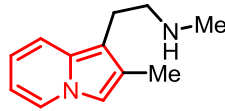
activity
Antihistamine

Figure 1. Biologically active propargylamines and indolizines. NNRTI: non-nucleoside reverse transcriptase inhibitor; VEGT: vascular endothelial growth factor.

only one example where the authors carry out a tandem multicomponent strategy has been described. ${ }^{67}$ Because of the scarce background found in the literature for this process using gold catalysts along with the interesting biological properties exhibited by indolizines, the search for novel efficient and ecofriendly protocols using benign catalysts still remains a challenging task.

With all these ideas in mind, we planned the preparation of new and challenging gold(I) ADC complexes. Moreover, the resulting carbenes could be promising catalysts in different organic processes. Here, we report on the synthesis of such $\mathrm{ADC}$ gold derivatives and the study of their applications in the synthesis of propargylamines and indolizines through MCRs.

\section{RESULTS AND DISCUSSION}

The common synthesis of metal acyclic carbenes is based on the nucleophilic attack of an amine over a metal isocyanide complex. This procedure does not proceed easily for all the amines, and in some cases with aryl or less activated amines, the reaction does not work. $^{71}( \pm)-1,2$-Cyclohexanediamine (2a), as a racemic mixture of trans isomers, has been employed by the first time for the preparation of gold $\mathrm{ADCs} 3 \mathbf{a}$ and $3 \mathbf{b}$ using isocyanides $\mathbf{1 a}$ and $\mathbf{1 b}$ following the reaction depicted in Scheme 1.

Acyclic carbenes $\mathbf{3 a}$ and $\mathbf{3 b}$ were easily prepared via the reaction of the isocyanide chloride gold(I) compound and the racemic mixture of 1,2-cyclohexanediamine (2a) at room temperature, giving rise to very good yields in both cases. It is remarkable that the mononuclear complexes are also obtained even in the case where a 2:1 molar ratio is used. Probably, the
Scheme 1. Synthesis of ADC Gold Carbene Complexes

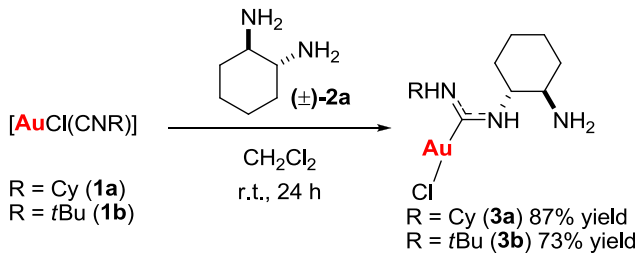

high insolubility of compounds $\mathbf{3 a}$ and $\mathbf{3 b}$ in dichloromethane is a driving force to solely produce the mononuclear species. Complexes $\mathbf{3 a}$ and $\mathbf{3 b}$ are sparingly soluble in common organic solvents. The ${ }^{1} \mathrm{H}$ NMR spectrum of complex $\mathbf{3 b}$ carried out in methanol- $d_{4}$ shows the expected resonances for the cyclohexyl skeleton, with two multiplets for the $-\mathrm{CH}-$ protons, four multiplets for the $-\mathrm{CH}_{2}-$ protons, and a singlet for the tertbutyl protons. The amine protons are not observed as they interchange with the deuterium of the solvent. In the ${ }^{13} \mathrm{C}$ attached proton test (APT) NMR spectrum, all the signals can be easily assigned (Figure S4) and corroborate the inequivalence of all the carbons in the cyclohexyl moiety, thus indicating that only one gold center has formed the ADC unit. The resonance due to the carbene carbon atom appears at $192.0 \mathrm{ppm}$.

In contrast, in complex $3 a$ because of the higher steric hindrance of the substituents and also because the carbene C$\mathrm{N}$ bond shows a considerable multiple character in this type of complexes, an important restriction to rotation is produced, giving rise to stereoisomers or rotamers (see Figure 2).

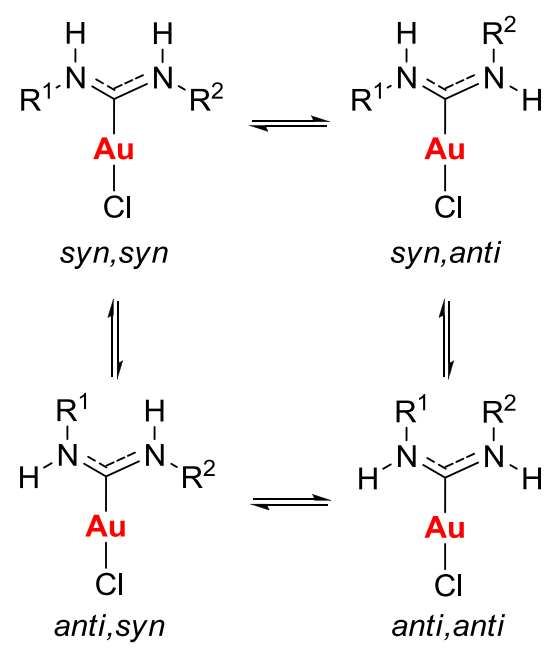

Figure 2. Different structural conformations for ADCs.

For this reason, complex 3a shows a very complicated ${ }^{1} \mathrm{H}$ NMR spectrum, and the resonances of the $-\mathrm{CH}_{2}-$ protons at the cyclohexyl ring appear as multiplets. It is possible to observe the resonances of the cyclohexyl $-\mathrm{CH}-$ protons in the less congested area in three different rotamers, with two of them in higher proportion. In the ${ }^{13} \mathrm{C}$-APT NMR spectrum, two resonances with different intensities are observed for the carbene carbon atoms, which are probably due to the two major rotamers. The matrix-assisted laser desorption ionization mass spectra show the cationic peak arising at the loss of the chlorine ligand for complex $3 \mathrm{a}$ at $m / z=420.1759[\mathrm{M}-\mathrm{Cl}]^{+}$ and both the molecular peak $[\mathrm{M}+\mathrm{H}]^{+}$at $m / z=430.1327$ and the cationic $[\mathrm{M}-\mathrm{Cl}]^{+}$at $m / z=394.1524$ for complex $3 \mathbf{b}$. 
Additionally, the analytical data for these complexes also agree with the proposed formulation. In the infrared (IR) spectra, the most significant absorptions are the $\nu(\mathrm{Au}-\mathrm{Cl})$, which appears at around $320 \mathrm{~cm}^{-1}$, and the $\nu(\mathrm{N}-\mathrm{H})$ in the range $2600-3000 \mathrm{~cm}^{-1}$.

With both gold complexes in hand and in the context of our research program focused on the development of new catalytic processes, we first centered our attention in the preparation of propargylamines 7 via the $\mathrm{A}^{3}$-coupling reaction following an easy and straightforward procedure. To test the efficiency of our precatalytic structures $\mathbf{3 a}, \mathbf{b}$, the viability of the reaction model illustrated in Table 1 was initially explored.

Table 1. Screening of the $\mathrm{A}^{3}$-Coupling Reaction ${ }^{a}$

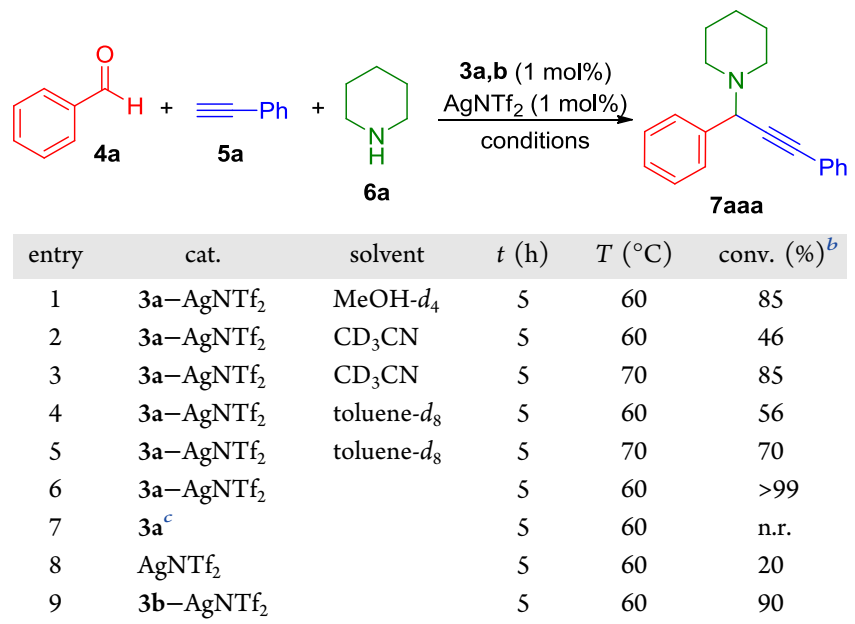

${ }^{a}$ Reaction conditions: benzaldehyde $4 \mathrm{a}(0.25 \mathrm{mmol})$, piperidine $6 \mathrm{a}$ $(0.275 \mathrm{mmol})$, phenylacetylene $5 \mathbf{a}(0.3 \mathrm{mmol}), 3 \mathbf{3 a}, \mathbf{b}(0.0025 \mathrm{mmol})$, $\operatorname{AgNTf}_{2}(0.0025 \mathrm{mmol})$, and solvent $0.7 \mathrm{~mL} .{ }^{b}$ The conversions of the reactions are given by ${ }^{1} \mathrm{H}$ NMR using mesitylene as the internal standard. ${ }^{c}$ Without addition of AgNTf $_{2}$.

In the first screening of solvent at $60^{\circ} \mathrm{C}$, encouraging results were found with $\mathrm{MeOH}-d_{4}$ for $1 \mathrm{~mol} \%$ of the catalyst (Table 1 , entry 1 ) after short reactions times $(5 \mathrm{~h})$. In contrast, with $\mathrm{CD}_{3} \mathrm{CN}$ and toluene- $d_{8}$, better conversions were only achieved when the temperature of the reaction was increased until $70^{\circ} \mathrm{C}$ for the same reaction time (entries 3 and 5). Interestingly, a complete conversion was observed when the reaction was performed in the absence of solvent at $60{ }^{\circ} \mathrm{C}$ after $5 \mathrm{~h}$ of the reaction (entry 6). It is worth noting that the gold precatalyst 3a does not promote the reaction in the absence of the Ag species (entry 7). The same is observed when the reaction was performed only with the cocatalyst $\mathrm{AgNTf}_{2}$ (entry 8). A good result was obtained using catalyst $\mathbf{3 b}$ (entry 9), although a slight lower conversion was observed in comparison with catalyst 3a. With the best reaction conditions found, different aldehydes $\mathbf{4 a}-\mathbf{c}$, acetylenes $\mathbf{5 a}, \mathbf{b}$, and amines $\mathbf{6 a}-\mathbf{f}$ were explored to extend the scope of the reaction. The results are shown in Table 2.

Very good results were obtained for the complete scope of the reaction using different cyclic secondary amines such as piperidine (6a), morpholine (6b), or pyrrolidines (6c and $6 e$ ) and even noncyclic secondary amines such as $\mathrm{Et}_{2} \mathrm{NH}(\mathbf{6 d})$ and $\mathrm{Bu}_{2} \mathrm{NH}(6 \mathbf{f})$. Good results were also achieved for the use of different aldehydes $(\mathbf{4 a - c})$ and acetylenes (5a and $\mathbf{5 b})$. For aldehydes $\mathbf{4 b}, \mathbf{c}$, which are solids, the addition of a small amount of $100 \mu \mathrm{L} \mathrm{CH}_{3} \mathrm{CN}$ was needed prior to the reaction.
Otherwise, the crude mixture becomes very dense, and the stirring is really difficult. It is remarkable that our work is one of the scarce examples in which a gold catalyst is used to promote this process, in addition of using very low catalyst loading $(1 \mathrm{~mol} \%)$ and short reaction times $(5 \mathrm{~h})$. Our reaction represents an improvement in the synthesis of propargylamines in comparison with other reported examples where several metal complexes or metal salts such as $\mathrm{Ag}(\mathrm{I}),{ }^{72} \mathrm{Cu}(\mathrm{I}){ }^{73}$ $\mathrm{Zn}(\mathrm{II}),{ }^{74,75}$ or $\mathrm{Ir}(\mathrm{II})^{76}$ have been employed, among others, because in our case lower catalyst loading, shorter reaction times, and lower temperature were able to promote the process. Moreover, this is one of the scarce examples where $\mathrm{Au}(\mathrm{I})$ has been used against the examples reported with $\mathrm{Au}$ (III) and even in the absence of solvent and without inert atmosphere. Additionally, in many cases, the authors only used their catalysts to obtain propargylamines. In contrast and encouraged by these results, following this simple and effective method, our next step was to apply this catalytic system in the synthesis of indolizines $\mathbf{8}$ (Table 3 ).

Under the same optimized reaction conditions, the corresponding 1 -aminoindolizine products 8 were obtained with very good yields in short reaction times. The generality of the protocol was evaluated by the synthesis of differently substituted 1 -aminoindolizines 8 . Thus, the reaction between pyridine-2-carboxaldehyde (4d) and 2-quinolinecarboxaldehyde (4e) with various secondary amines and terminal alkynes $\mathbf{5 a}, \mathbf{b}$ affords the desired product in all cases using $1 \mathrm{~mol} \%$ of catalysts 3a. Interestingly, less studied alkynes 5c and 5d also provided the corresponding final products with moderate yields, although the starting material remained unreacted. Maybe longer reaction times would afford better yields. When the process was performed with aldehyde $4 \mathrm{~d}$, the reactions worked with cyclic secondary amines $\mathbf{6 a}-\mathbf{c}$ and even noncyclic secondary amines $\mathbf{6 d , f}$, more scarcely employed until now in this process. Interestingly, 2-quinolinecarboxaldehyde (4e) was also efficiently employed in the reaction with piperidine $6 a$ and different noncyclic secondary amines $\mathbf{6} \mathbf{d}, \mathbf{f}, \mathbf{g}$, giving rise to the corresponding aminoindolizine products 8 with very good results. On the other hand, when aldehyde $4 \mathbf{e}$ was used, the final products were obtained with yield values that were a bit lower compared with those achieved with $\mathbf{4 d}$. In order to check the effectiveness of catalyst $3 \mathbf{b}$, we tested some model reactions, and in all of them, very good results were obtained (Table 3).

The formation of the propargylamines 7 and the corresponding indolizines 8 can be explained by a plausible mechanism depicted in Scheme 2 and based on the chemistry of gold $^{14-23}$ (routes a and b). In both cases, the aldehyde initially reacts with the secondary amine to generate the iminium ion A. Because the bases present in the reaction are not able to deprotonate the terminal alkyne by themselves, the formation of an intermediate $\pi$-metal-alkyne complex is envisioned, involving a $\mathrm{C}-\mathrm{H}$ activation of the alkyne by the gold catalyst. Complex B should make the alkyne proton more acidic for further abstraction. The in situ generated metal acetylide $\mathbf{C}$ reacts with the iminium ion $\mathbf{A}$, giving rise to the formation of the propargylamines 7 , releasing the gold catalyst for the subsequent catalytic cycle (Scheme 2, route a). Otherwise, if we have a pyridine aldehyde derivative (Scheme 2 , route $b$ ) once the corresponding propargylamine $\mathbf{D}$ is generated, it undergoes a cyclization (5 endo-dig) affording intermediate $\mathbf{E}$. In this step, a plausible activation of the alkyne by the metal to allow the cyclization is assumed. A subsequent 
Table 2. Catalytic Synthesis of Propargylamines 7 via the Three-Component Addition Reaction

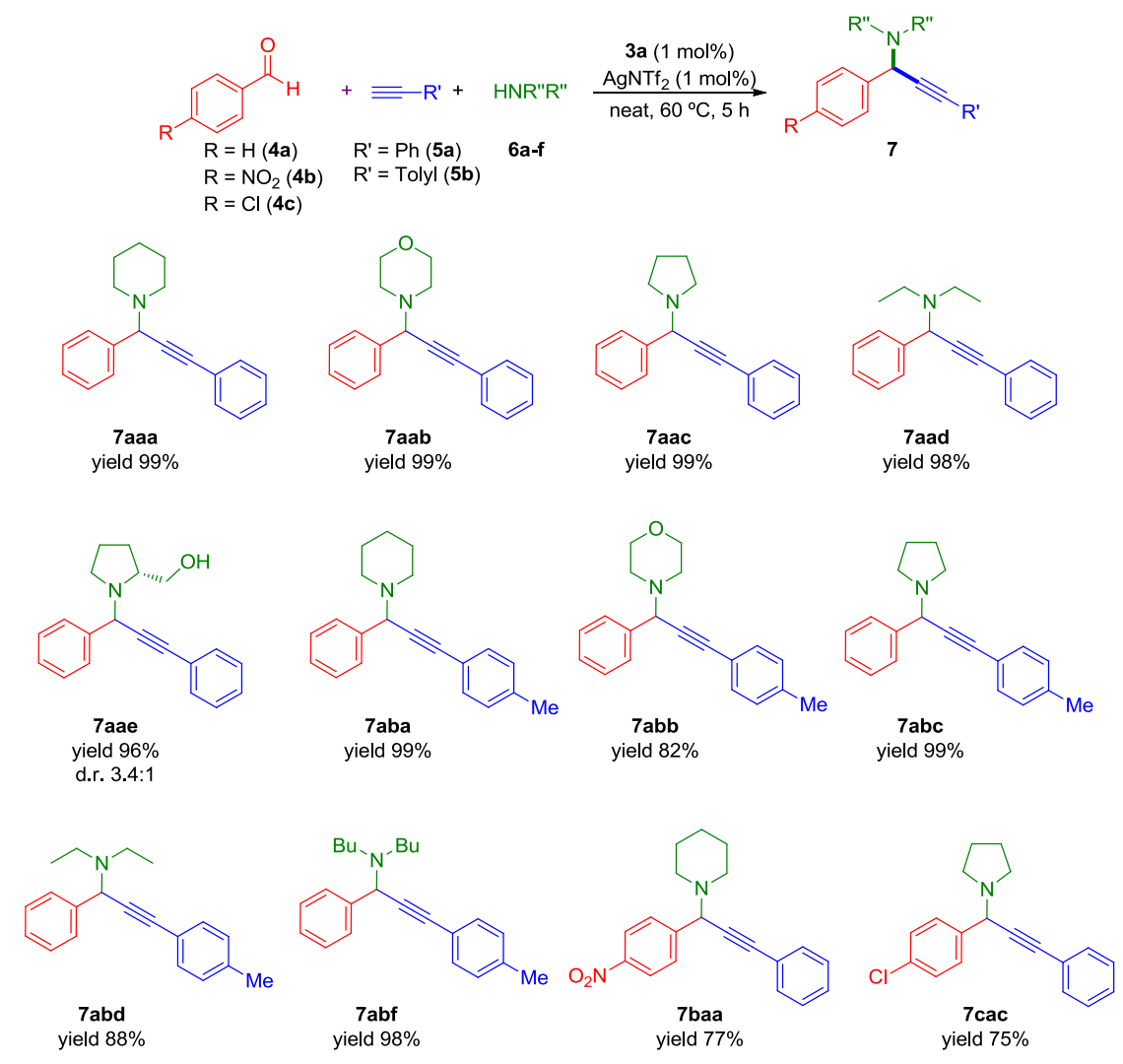

isomerization of $\mathbf{E}$ and final protodeauration of $\mathbf{F}$ would release the gold catalyst to start with the catalytic cycle.

At this stage, we planned to synthesize chiral-related catalysts following the same synthetic procedure (Scheme 3 ). For such a purpose, chiral amines $\mathbf{2 b}$ and $\mathbf{2 c}$ were selected. Chiral symmetric carbene $3 c$ and nonsymmetric carbene $3 d$ were easily prepared via the reaction of isocyanide $\mathbf{1 a}$ and the chiral amines $\mathbf{2 b}$ and $\mathbf{2 c}$, affording the chiral ADCs in very good yields.

Surprisingly, the chiral complex $3 c$, which is analogous to the racemic mixture $\mathbf{3 a}$, was obtained as the dinuclear species. As this compound has a greater solubility in dichloromethane, it does not precipitate from the reaction media, and then the reaction proceeds to the complete nucleophilic attack of both amine units. To shed more light on this matter, we have measured the optical rotation of compound 3a in methanol, which interestingly has a slightly different value from zero $\left([\alpha]_{\mathrm{D}}^{20}-1.12\right)$, whereas the optical rotation of complex $3 \mathrm{c}$ is $[\alpha]_{\mathrm{D}}^{20}-26.07$. Therefore, we propose that there was a slight enrichment in one of the enantiomers $(1 S, 2 S)$ because of the high insolubility of this mononuclear species compared to that of the dinuclear $3 \mathrm{c}$, which is the $1 R, 2 R$ enantiomer.

The analytical data and the mass spectrum corroborate the proposed formulation. Complex $3 \mathrm{c}$ shows NMR spectra with a different integral ratio for the cyclohexyl protons, similar to that of the racemic mixture $3 \mathrm{a}$, with the presence of rotamers. In this case, three resonances for the carbene carbon atom are clearly observed at $190.9,185.9$, and $185.8 \mathrm{ppm}$, indicating the presence of three different rotamers. For complex $3 \mathrm{~d}$, three rotamers are also clearly observed in the ${ }^{1} \mathrm{H}$ NMR spectrum for the resonances of the tolyl group. The $\nu(\mathrm{Au}-\mathrm{Cl})$ and $\nu(\mathrm{N}-\mathrm{H})$ absorptions are also observed in the IR spectra of these compounds. The analytical data for both complexes agree with the proposed formulation.

Interestingly, with these two chiral structures, we have demonstrated the possibility to easily obtain chiral or unsymmetrically substituted ADCs, also using substituents with steric properties, which is still a challenging task in the preparation of NHCs. Furthermore, we set out on the exploration of the reactivity of these promising structures to generate propargylamines $7 \mathbf{a a a}$ and $7 \mathbf{a a b}$. Although at this point only $<10 \%$ of enantiomeric excess has been reached in a model reaction between benzaldehyde $4 \mathrm{a}$, phenylacetylene 5a, and morpholine $\mathbf{6} \mathbf{b}$, more efforts are necessary to improve these values and they are currently ongoing in our lab.

\section{CONCLUSIONS}

In summary, new gold(I) ADCs have been synthesized following a straightforward protocol. This synthetic method of the ADC metal complexes offers a great versatility for the synthesis of gold(I) species with different scaffolds, including chiral derivatives. These precatalysts have resulted to be efficient for the preparation of propargylamines and indolizines. These interesting scaffolds have been achieved following an easy and green protocol by a three-component coupling of carboxaldehydes, secondary amines and terminal alkynes. The potential of our procedure is reflected by the substrate scope, the operational simplicity, short reaction times, and good to excellent isolated yields. We believe that these MCRs demonstrate the strong capacity of our complex to act as an efficient catalyst. In addition, the reactions were performed under solvent-free conditions, an important feature from a sustainable point of view, without inert atmosphere and in the presence of light, in contrast to previous reported 
Table 3. Scope for the Gold(I)-Catalyzed Multicomponent Synthesis of Aminoindolizines 8

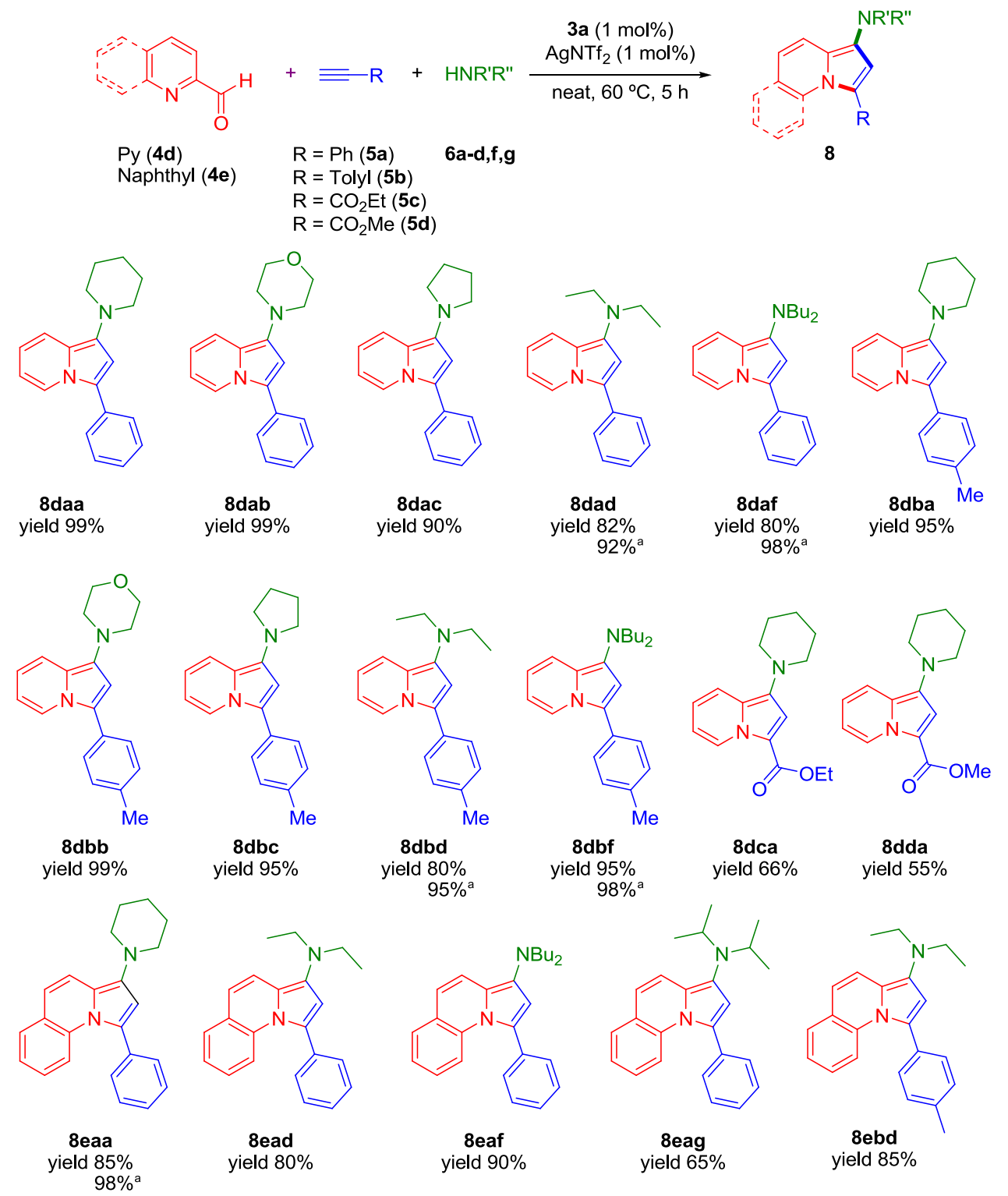

${ }^{a}$ Results obtained with catalyst $\mathbf{3 b}$.

examples. The chiral version of these catalysts has also been synthesized, and the asymmetric catalysis in the reaction of propargylamines has been tried. The results were not good probably because the chiral center is far from the catalytic site of the complex. We cannot discard that the free single bond rotations in the chiral catalysts, leading to multiple transition states, would also be responsible for the low ee. Further studies to improve the design of the catalysts are ongoing in our laboratory.

\section{EXPERIMENTAL DETAILS}

Instrumentation. Purification of reaction products was carried out by column chromatography using silica gel (0.063$0.200 \mathrm{~mm})$. Analytical thin-layer chromatography was performed on $0.25 \mathrm{~mm}$ silica gel $60-\mathrm{F}$ plates. ${ }^{1} \mathrm{H}$ and ${ }^{13} \mathrm{C}$ $\left\{{ }^{1} \mathrm{H}\right\}$-APT NMR spectra were recorded at room temperature on a Bruker AVANCE 400 spectrometer $\left({ }^{1} \mathrm{H}, 400 \mathrm{MHz} ;{ }^{13} \mathrm{C}\right.$, $100.6 \mathrm{MHz}$ ) or on a Bruker AVANCE II 300 spectrometer $\left({ }^{1} \mathrm{H}, 300 \mathrm{MHz} ;{ }^{13} \mathrm{C}, 75.5 \mathrm{MHz}\right)$, with chemical shifts (ppm) reported relative to the solvent peaks of the deuterated solvent. $\mathrm{CDCl}_{3}, \mathrm{CD}_{2} \mathrm{Cl}_{2}, \mathrm{CD}_{3} \mathrm{COCD}_{3}$, and $\mathrm{CD}_{3} \mathrm{OD}$ were used as the deuterated solvents. Chemical shifts were reported in the $\delta$ scale relative to residual $\mathrm{CHCl}_{3}(7.28 \mathrm{ppm}), \mathrm{CH}_{2} \mathrm{Cl}_{2}$ (5.32 ppm), $\mathrm{CH}_{3} \mathrm{COCH}_{3}$ (2.05 ppm), and $\mathrm{CH}_{3} \mathrm{OH}$ (3.31) for ${ }^{1} \mathrm{H}$ $\mathrm{NMR}$ and to the central line of $\mathrm{CDCl}_{3}(77 \mathrm{ppm}), \mathrm{CD}_{2} \mathrm{Cl}_{2}(54$ $\mathrm{ppm}$ ), $\mathrm{CD}_{3} \mathrm{COCD}_{3}$ (29.84 ppm), and $\mathrm{CD}_{3} \mathrm{OD}$ (49.0 ppm) for ${ }^{13} \mathrm{C}$-APT-NMR. Mass spectra were recorded on Bruker ESQUIRE 3000 PLUS, with the electrospray ionization technique. The attenuated total reflection (ATR)-Fourier transform infrared (FTIR) spectra of solid samples were recorded on a PerkinElmer FTIR spectrometer equipped with a universal ATR sampling accessory.

Starting Materials. All reactions were performed under air atmosphere and solvents were used as received without further purification or drying. The starting materials $[\mathrm{AuCl}(\mathrm{CNR})]$ were prepared according to published procedures. ${ }^{77-79}$ Starting materials, yields, and spectroscopic data for compounds $7 \mathbf{a b f}, \mathbf{8 d a d}, \mathbf{8 d b f}$, 8ead, 8eag, and 8 ebd are described 
Scheme 2. Plausible Mechanistic Reaction

Synthesis of propargylamines (route a)<smiles>[R]N[CH+]C(=O)c1ccccc1</smiles>

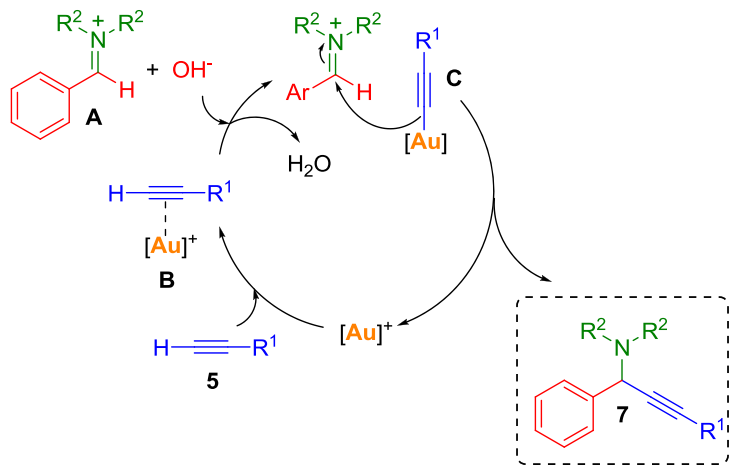

Synthesis of indolizines (route b)

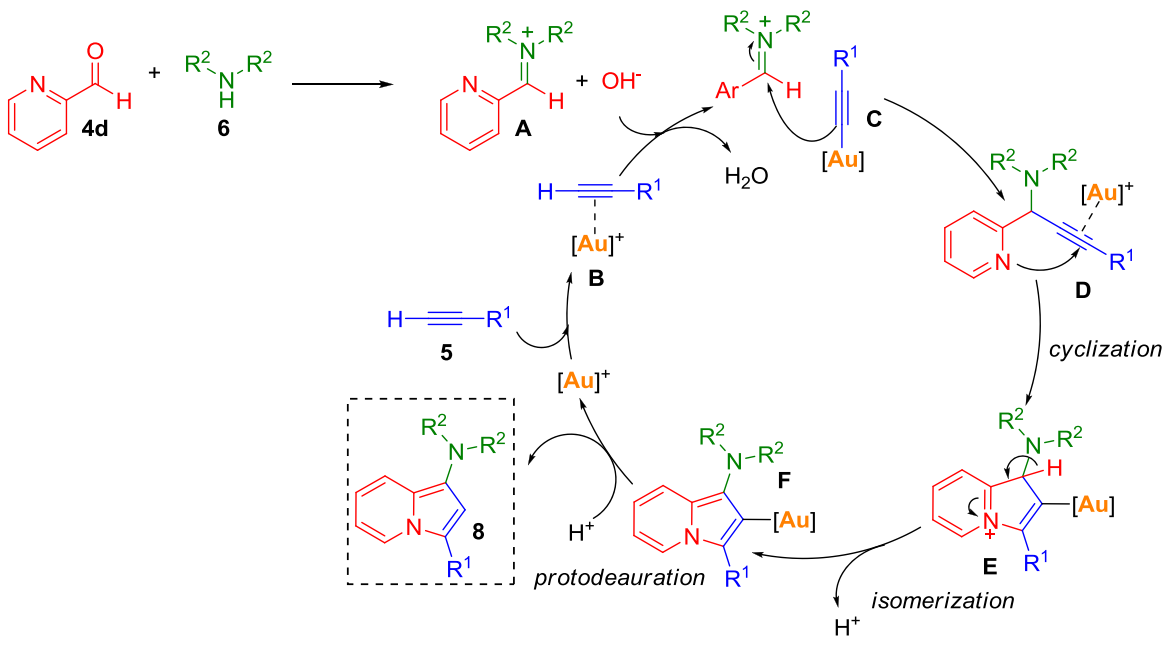

Scheme 3. Synthesis of Chiral Gold ADCs

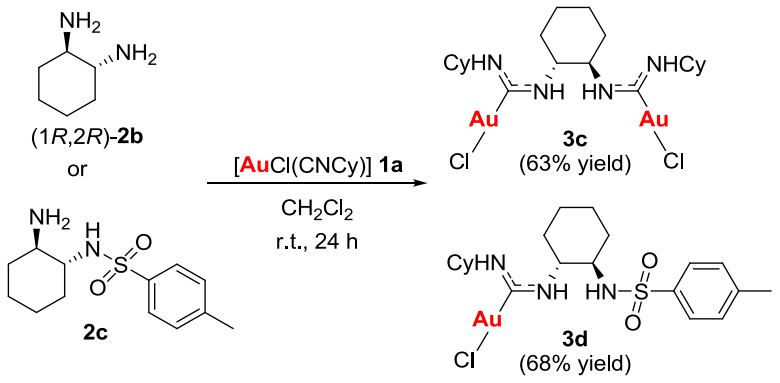

in the Supporting Information. ${ }^{1} \mathrm{H}$ and ${ }^{13} \mathrm{C}$ NMR spectra for compounds 7aaa, ${ }^{80} 7 \mathbf{a a b},{ }^{81} \mathbf{7 a a c}^{81}{ }^{8} \mathbf{a a d},{ }^{81} 7 \mathbf{a b a},{ }^{82} 7 \mathbf{a b b},{ }^{83}$ 7abc, ${ }^{84} \mathbf{7 a b d}^{85}{ }^{85} \mathbf{b a a},{ }^{86} \mathbf{7 c a c}^{87}{ }^{8 \mathrm{daa}},{ }^{67} \mathbf{8 d a b},{ }^{67} \mathbf{8 d a c}^{67}{ }^{6 \mathrm{daf}},{ }^{88}$ $\mathbf{8 d b a},{ }^{88} \mathbf{8 d b b},{ }^{89} \mathbf{8 e a a},{ }^{67}$ and $8 \mathbf{e a f}^{90}$ are consistent with the values previously reported in the literature.

General Procedure for the Synthesis of Complexes 3a-d. A mixture of $[\mathrm{AuCl}(\mathrm{CNR})] \mathrm{R}=\mathrm{Cy}(0.0683 \mathrm{~g}, 0.2$ $\mathrm{mmol}), \mathrm{R}={ }^{t} \mathrm{Bu}(0.0613 \mathrm{~g}, 0.2 \mathrm{mmol})$ and 1,2-cyclohexanediamine (as a racemic mixture of trans isomers, 2a) (0.0228 g, $0.2 \mathrm{mmol})$ or $(1 R, 2 R)-1,2$-cyclohexanediamine $(2 \mathbf{b})(0.0114 \mathrm{~g}$, $0.1 \mathrm{mmol})$ or $(1 R, 2 R)-(-)-N$-p-tosyl-1,2-cyclohexanediamine (2c) $(0.0537 \mathrm{~g}, 0.2 \mathrm{mmol})$ in dichloromethane $(20 \mathrm{~mL})$ was stirred at room temperature for $24 \mathrm{~h}(3 \mathbf{a}, \mathbf{b}, \mathbf{d})$ or 4 days $(3 \mathbf{c})$. Complexes $\mathbf{3} \mathbf{a}$ and $\mathbf{3 b}$ precipitated as white solids and were filtered off. For compounds $3 \mathbf{c}$ and $3 \mathbf{d}$, the volume was reduced to $5 \mathrm{~mL}$, and addition of $n$-hexane afforded the complexes as white solids.
General Procedure for the Au-Catalyzed ThreeComponent Synthesis of Propargylamines 7. To a mixture of gold complex 3a $(2 \mathrm{mg}, 0.0025 \mathrm{mmol})$ and AgNTf $_{2}(0.97 \mathrm{mg}, 0.0025 \mathrm{mmol})$, aldehyde $4 \mathrm{a}-\mathrm{c}(0.25$ $\mathrm{mmol})$, amine $\mathbf{6 a}-\mathbf{f}(0.275 \mathrm{mmol})$, and acetylene $\mathbf{5 a}, \mathbf{b}(0.30$ $\mathrm{mmol})$ were added under solvent-free conditions. The resulting reaction mixture was stirred at $60{ }^{\circ} \mathrm{C}$ for $5 \mathrm{~h}$ and monitored by thin-layer chromatography. After this reaction time, products 7 were isolated by flash chromatography $\left(\mathrm{SiO}_{2}\right.$, using $\mathrm{Hex} / \mathrm{Et}_{2} \mathrm{O}$ 95:5). The yields are reported in Table 2.

General Procedure for the Au-Catalyzed ThreeComponent Synthesis of Indolizines 8. To a mixture of gold complex 3a $(3.99 \mathrm{mg}, 0.005 \mathrm{mmol})$ and $\operatorname{AgNTf}_{2}(1.94$ $\mathrm{mg}, 0.005 \mathrm{mmol})$, aldehyde $4 \mathrm{~d}, \mathbf{e}(0.50 \mathrm{mmol})$, amine $\mathbf{6 a}-\mathbf{d}, \mathbf{f}$, g $(0.55 \mathrm{mmol})$, and acetylene $5 \mathbf{a}, \mathbf{b}(0.60 \mathrm{mmol})$ were added under solvent-free conditions. The resulting reaction mixture was stirred at $60{ }^{\circ} \mathrm{C}$ for $5 \mathrm{~h}$ and monitored by thin-layer chromatography. After the reaction time, products 8 were isolated by flash chromatography $\left(\mathrm{SiO}_{2}\right.$, using $\mathrm{Hex} / \mathrm{Et}_{2} \mathrm{O}$ 95:5). The yields are reported in Table 3.

\section{ASSOCIATED CONTENT}

\section{Supporting Information}

The Supporting Information is available free of charge on the ACS Publications website at DOI: 10.1021/acsomega.8b01352.

Characterization of all new compounds and ${ }^{1} \mathrm{H}$ and ${ }^{13} \mathrm{C}$ -

APT NMR spectra (PDF) 


\section{AUTHOR INFORMATION}

\section{Corresponding Authors}

*E-mail: raquelph@unizar.es (R.P.H.).

*E-mail: gimeno@unizar.es (M.C.G.).

\section{ORCID $\odot$}

Raquel P. Herrera: 0000-0002-5244-9569

M. Concepción Gimeno: 0000-0003-0553-0695

\section{Author Contributions}

The manuscript was written through contributions of all authors. All authors have given approval to the final version of the manuscript.

\section{Notes}

The authors declare no competing financial interest.

\section{ACKNOWLEDGMENTS}

This work is dedicated to Professor Antonio Laguna in recognition of his outstanding contribution to modern organometallic chemistry, on the occasion of his 70th birthday. The authors thank the Ministerio de Economia y Competitividad (MINECO/FEDER CTQ2016-75816-C2-1-P and CTQ2017-88091-P) and Gobierno de Aragón-Fondo Social Europeo (E07 17R) for the financial support of our research. M.A.-L. thanks the MINECO for a predoctoral fellowship.

\section{REFERENCES}

(1) Tiekink, E. R. T. Gold Compounds in Medicine: Potential AntiTumour Agents. Gold Bull. 2003, 36, 117-124.

(2) Maia, P. I. d. S.; Deflon, V. M.; Abram, U. Gold(III) complexes in medicinal chemistry. Future Med. Chem. 2014, 6, 1515-1536.

(3) Berners-Price, S. J.; Filipovska, A. Gold compounds as therapeutic agents for human diseases. Metallomics 2011, 3, 863-873.

(4) Ott, I. On the medicinal chemistry of gold complexes as anticancer drugs. Coord. Chem. Rev. 2009, 253, 1670-1681.

(5) Bertrand, B.; Casini, A. A golden future in medicinal inorganic chemistry: the promise of anticancer gold organometallic compounds. Dalton Trans. 2014, 43, 4209-4219.

(6) Zou, T.; Lum, C. T.; Lok, C.-N.; Zhang, J.-J.; Che, C.-M. Chemical biology of anticancer gold(III) and gold(I) complexes. Chem. Soc. Rev. 2015, 44, 8786-8801.

(7) Yeo, C.; Ooi, K.; Tiekink, E. Gold-Based Medicine: A Paradigm Shift in Anti-Cancer Therapy? Molecules 2018, 23, 1410.

(8) Visbal, R.; Fernández-Moreira, V.; Marzo, I.; Laguna, A.; Gimeno, M. C. Cytotoxicity and biodistribution studies of luminescent $\mathrm{Au}(\mathrm{I})$ and $\mathrm{Ag}(\mathrm{I}) \mathrm{N}$-heterocyclic carbenes. Searching for new biological targets. Dalton Trans. 2016, 45, 15026-15033.

(9) Gutiérrez, A.; Gracia-Fleta, L.; Marzo, I.; Cativiela, C.; Laguna, A.; Gimeno, M. C. Gold(I) thiolates containing amino acid moieties. Cytotoxicity and structure-activity relationship studies. Dalton Trans. 2014, 43, 17054-17066.

(10) Goitia, H.; Nieto, Y.; Villacampa, M. D.; Kasper, C.; Laguna, A.; Gimeno, M. C. Antitumoral Gold and Silver Complexes with Ferrocenyl-Amide Phosphines. Organometallics 2013, 32, 6069-6078.

(11) Crespo, O.; Gimeno, M. C.; Laguna, A.; Larraz, C.; Villacampa, M. D. Highly Luminescent Gold(I)-Silver(I) and Gold(I)-Copper(I) Chalcogenide Clusters. Chem.-Eur. J. 2007, 13, 235-246.

(12) Czerwieniec, R.; Hofbeck, T.; Crespo, O.; Laguna, A.; Gimeno, M. C.; Yersin, H. The Lowest Excited State of Brightly Emitting Gold(I) Triphosphine Complexes. Inorg. Chem. 2010, 49, 37643767.

(13) Crespo, O.; Gimeno, M. C.; Jones, P. G.; Laguna, A.; López-deLuzuriaga, J. M.; Monge, M.; Pérez, J. L.; Ramón, M. A. Luminescentnido-Carborane-Diphosphine Anions $\left[\left(\mathrm{PR}_{2}\right)_{2} \mathrm{C}_{2} \mathrm{~B}_{9} \mathrm{H}_{10}\right]^{-}\left(\mathrm{R}=\mathrm{Ph},{ }^{\mathrm{i}} \mathrm{Pr}\right)$. Modification of Their Luminescence Properties upon Formation of Three-Coordinate Gold(I) Complexes. Inorg. Chem. 2003, 42, 2061-2068.
(14) Hashmi, A. S. K.; Hutchings, G. J. Gold Catalysis. Angew. Chem., Int. Ed. 2006, 45, 7896-7936.

(15) Hashmi, A. S. K. Gold-Catalyzed Organic Reactions. Chem. Rev. 2007, 107, 3180-3211.

(16) Fürstner, A.; Davies, P. W. Catalytic Carbophilic Activation: Catalysis by Platinum and Gold $\pi$ Acids. Angew. Chem., Int. Ed. 2007, 46, 3410-3449.

(17) Li, Z.; Brouwer, C.; He, C. Gold-Catalyzed Organic Transformations. Chem. Rev. 2008, 108, 3239-3265.

(18) Arcadi, A. Alternative Synthetic Methods through New Developments in Catalysis by Gold. Chem. Rev. 2008, 108, 32663325.

(19) Jiménez-Nuñez, E.; Echavarren, A. M. Gold-Catalyzed Cycloisomerizations of Enynes: A Mechanistic Perspective. Chem. Rev. 2008, 108, 3326-3350.

(20) Gorin, D. J.; Sherry, B. D.; Toste, F. D. Ligand Effects in Homogeneous Au Catalysis. Chem. Rev. 2008, 108, 3351-3378.

(21) Garayalde, D.; Nevado, C. Synthetic applications of goldcatalyzed ring expansions. Beilstein J. Org. Chem. 2011, 7, 767-780.

(22) Rudolph, M.; Hashmi, A. S. K. Gold catalysis in total synthesis-an update. Chem. Soc. Rev. 2012, 41, 2448-2462.

(23) Sengupta, S.; Shi, X. Recent Advances in Asymmetric Gold Catalysis. Chem CatChem 2010, 2, 609-619.

(24) Lin, I. J. B.; Vasam, C. S. Review of gold(I) N-heterocyclic carbenes. Can. J. Chem. 2005, 83, 812-825.

(25) Schuster, O.; Yang, L.; Raubenheimer, H. G.; Albrecht, M. Beyond Conventional N-Heterocyclic Carbenes: Abnormal, Remote, and Other Classes of NHC Ligands with Reduced Heteroatom Stabilization. Chem. Rev. 2009, 109, 3445-3478.

(26) Díez-González, S.; Marion, N.; Nolan, S. P. N-Heterocyclic Carbenes in Late Transition Metal Catalysis. Chem. Rev. 2009, 109, 3612-3676.

(27) Nolan, S. P. The Development and Catalytic Uses of NHeterocyclic Carbene Gold Complexes. Acc. Chem. Res. 2011, 44, 91-100.

(28) Oehninger, L.; Rubbiani, R.; Ott, I. N-Heterocyclic carbene metal complexes in medicinal chemistry. Dalton Trans. 2013, 42, 3269-3284.

(29) Liu, W.; Gust, R. Metal N-heterocyclic carbene complexes as potential antitumor metallodrugs. Chem. Soc. Rev. 2013, 42, 755-773.

(30) Visbal, R.; Gimeno, M. C. N-heterocyclic carbene metal complexes: photoluminescence and applications. Chem. Soc. Rev. 2014, 43, 3551-3574

(31) Boyarskiy, V. P.; Luzyanin, K. V.; Kukushkin, V. Y. Acyclic diaminocarbenes (ADCs) as a promising alternative to $\mathrm{N}$-heterocyclic carbenes (NHCs) in transition metal catalyzed organic transformations. Coord. Chem. Rev. 2012, 256, 2029-2056.

(32) Slaughter, L. M. Acyclic Aminocarbenes in Catalysis. ACS Catal. 2012, 2, 1802-1816.

(33) Barbazanges, M.; Fensterbank, L. Chiral Acyclic Diaminocarbene Complexes: a New Opportunity for Gold Asymmetric Catalysis. ChemCatChem 2012, 4, 1065-1066.

(34) Multicomponent Reactions; Zhu, J., Bienaymé, H., Eds.; WileyVCH: Weinheim, 2005.

(35) Multicomponent Reactions: Concepts and Applications for Design and Synthesis; Herrera, R. P., Marqués-López, E., Eds.; John Wiley \& Sons: Hoboken, New Jersey, 2015.

(36) Wei, C.; Li, Z.; Li, C.-J. The Development of $\mathrm{A}^{3}$-Coupling (Aldehyde-Alkyne-Amine) and $\mathrm{AA}^{3}$-Coupling (Asymmetric Aldehyde-Alkyne-Amine). Synlett 2004, 1472-1483.

(37) Yoo, W.-Y.; Zhao, L.; Li, C.-J. The A ${ }^{3}$-Coupling (AldehydeAlkyne-Amine) Reaction: A Versatile Method for the Preparation of Propargylamines. Aldrichimica Acta 2011, 44, 43-51.

(38) Peshkov, V. A.; Pereshivko, O. P.; Van der Eycken, E. V. A walk around the $A^{3}$-coupling. Chem. Soc. Rev. 2012, 41, 3790-3807.

(39) Abbiati, G.; Rossi, E. Silver and gold-catalyzed multicomponent reactions. Beilstein J. Org. Chem. 2014, 10, 481-513. 
(40) Lauder, K.; Toscani, A.; Scalacci, N.; Castagnolo, D. Synthesis and Reactivity of Propargylamines in Organic Chemistry. Chem. Rev. 2017, 117, 14091-14200.

(41) Huffman, M. A.; Yasuda, N.; DeCamp, A. E.; Grabowski, E. J. J. Lithium Alkoxides of Cinchona Alkaloids as Chiral Controllers for Enantioselective Acetylide Addition to Cyclic N-Acyl Ketimines. J. Org. Chem. 1995, 60, 1590-1594.

(42) Kauffman, G. S.; Harris, G. D.; Dorow, R. L.; Stone, B. R. P.; Parsons, R. L.; Pesti, J. A.; Magnus, N. A.; Fortunak, J. M.; Confalone, P. N.; Nugent, W. A. An Efficient Chiral Moderator Prepared from Inexpensive (+)-3-Carene: Synthesis of the HIV-1 Non-Nucleoside Reverse Transcriptase Inhibitor DPC 963. Org. Lett. 2000, 2, 31193121.

(43) Jiang, B.; Xu, M. Highly Enantioselective Construction of Fused Pyrrolidine Systems That Contain a Quaternary Stereocenter: Concise Formal Synthesis of (+)-Conessine. Angew. Chem., Int. Ed. 2004, 43, 2543-2546.

(44) Gommermann, N.; Knochel, P. Practical highly enantioselective synthesis of terminal propargylamines. An expeditious synthesis of (S)-(+)-coniine. Chem. Commun. 2004, 2324-2325.

(45) Xu, Q.; Rozners, E. Asymmetric Synthesis of trans-3,4-Dialkyl$\gamma$-butyrolactones via an Acyl-Claisen and Iodolactonization Route. Org. Lett. 2005, 7, 2821-2824.

(46) Langston, J.; Irwin, I.; Langston, E.; Forno, L. Pargyline prevents MPTP-induced parkinsonism in primates. Science 1984, 225, $1480-1482$

(47) Chen, J. J.; Swope, D. M. Clinical Pharmacology of Rasagiline: A Novel, Second-Generation Propargylamine for the Treatment of Parkinson Disease. J. Clin. Pharmacol. 2005, 45, 878-894.

(48) Birks, J.; Flicker, L. Selegiline for Alzheimer's disease. Cochrane Database of Systematic Reviews; John Wiley \& Sons, Ltd: Chichester, U.K., 2003; Vol. 1.

(49) Baranyi, M.; Porceddu, P. F.; Gölöncsér, F.; Kulcsár, S.; Otrokocsi, L.; Kittel, A.; Pinna, A.; Frau, L.; Huleatt, P. B.; Khoo, M.L.; Chai, C. L. L.; Dunkel, P.; Mátyus, P.; Morelli, M.; Sperlágh, B. Novel (Hetero)arylalkenyl propargylamine compounds are protective in toxin-induced models of Parkinson's disease. Mol. Neurodegener. 2016, 11,6

(50) Bolea, I.; Gella, A.; Unzeta, M. Propargylamine-derived multitarget-directed ligands: fighting Alzheimer's disease with monoamine oxidase inhibitors. J. Neural Transm. 2013, 120, 893-902.

(51) Wei, C.; Li, C.-J. A Highly Efficient Three-Component Coupling of Aldehyde, Alkyne, and Amines via $\mathrm{C}-\mathrm{H}$ Activation Catalyzed by Gold in Water. J. Am. Chem. Soc. 2003, 125, 9584-9585.

(52) Kantam, M. L.; Prakash, B. V.; Reddy, C. R.; Sreedhar, B. Layered Double Hydroxide-Supported Gold Catalyst for ThreeComponent Aldehyde-Amine-Alkyne Coupling. Synlett 2005, 23292332.

(53) Lo, V. K.-Y.; Liu, Y.; Wong, M.-K.; Che, C.-M. Gold(III) Salen Complex-Catalyzed Synthesis of Propargylamines via a ThreeComponent Coupling Reaction. Org. Lett. 2006, 8, 1529-1532.

(54) Kidwai, M.; Bansal, V.; Kumar, A.; Mozumdar, S. The first Aunanoparticles catalyzed green synthesis of propargylamines via a threecomponent coupling reaction of aldehyde, alkyne and amine. Green Chem. 2007, 9, 742-745.

(55) Lo, V. K.-Y.; Kung, K. K.-Y.; Wong, M.-K.; Che, C.-M. Gold $(\mathrm{III})\left(\mathrm{C}^{\wedge} \mathrm{N}\right)$ complex-catalyzed synthesis of propargylamines via a three-component coupling reaction of aldehydes, amines and alkynes. J. Organomet. Chem. 2009, 694, 583-591.

(56) Elie, B. T.; Levine, C.; Ubarretxena-Belandia, I.; VarelaRamírez, A.; Aguilera, R. J.; Ovalle, R.; Contel, M. Water-Soluble (Phosphane)gold(I) Complexes - Applications as Recyclable Catalysts in a Three-Component Coupling Reaction and as Antimicrobial and Anticancer Agents. Eur. J. Inorg. Chem. 2009, 3421-3430.

(57) Lili, L.; Xin, Z.; Jinsen, G.; Chunming, X. Engineering metalorganic frameworks immobilize gold catalysts for highly efficient onepot synthesis of propargylamines. Green Chem. 2012, 14, 1710-1720.

(58) Kung, K. K.-Y.; Lo, V. K.-Y.; Ko, H.-M.; Li, G.-L.; Chan, P.-Y.; Leung, K.-C.; Zhou, Z.; Wang, M.-Z.; Che, C.-M.; Wong, M.-K.
Cyclometallated Gold(III) Complexes as Effective Catalysts for Synthesis of Propargylic Amines, Chiral Allenes and Isoxazoles. Adv. Synth. Catal. 2013, 355, 2055-2070.

(59) Montanel-Pérez, S.; Herrera, R. P.; Laguna, A.; Villacampa, M. D.; Gimeno, M. C. The fluxional amine gold(III) complex as an excellent catalyst and precursor of biologically active acyclic carbenes. Dalton Trans. 2015, 44, 9052-9062.

(60) von Wachenfeldt, H.; Polukeev, A. V.; Loganathan, N.; Paulsen, F.; Röse, P.; Garreau, M.; Wendt, O. F.; Strand, D. Cyclometallated gold(III) aryl-pyridine complexes as efficient catalysts for threecomponent synthesis of substituted oxazoles. Dalton Trans. 2015, 44, $5347-5353$

(61) Zhang, X.; Corma, A. Supported Gold(III) Catalysts for Highly Efficient Three-Component Coupling Reactions. Angew. Chem., Int. Ed. 2008, 47, 4358-4361.

(62) Liu, Y. Recent advances on diversity oriented heterocycle synthesis via multicomponent tandem reactions based on $\mathrm{A}^{3}$ coupling. ARKIVOC 2014, No. i, 1-20.

(63) Sadowski, B.; Klajn, J.; Gryko, D. T. Recent advances in the synthesis of indolizines and their $\pi$-expanded analogues. Org. Biomol. Chem. 2016, 14, 7804-7828.

(64) Singh, G. S.; Mmatli, E. E. Recent progress in synthesis and bioactivity studies of indolizines. Eur. J. Med. Chem. 2011, 46, 52375257.

(65) Seregin, I. V.; Gevorgyan, V. Gold-Catalyzed 1,2-Migration of Silicon, Tin, and Germanium en Route to C-2 Substituted Fused Pyrrole-Containing Heterocycles. J. Am. Chem. Soc. 2006, 128, 12050-12051.

(66) Schwier, T.; Sromek, A. W.; Yap, D. M. L.; Chernyak, D.; Gevorgyan, V. Mechanistically Diverse Copper-, Silver-, and GoldCatalyzed Acyloxy and Phosphatyloxy Migrations: Efficient Synthesis of Heterocycles via Cascade Migration/Cycloisomerization Approach. J. Am. Chem. Soc. 2007, 129, 9868-9878.

(67) Yan, B.; Liu, Y. Gold-Catalyzed Multicomponent Synthesis of Aminoindolizines from Aldehydes, Amines, and Alkynes under Solvent-Free Conditions or in Water. Org. Lett. 2007, 9, 4323-4326.

(68) Seregin, I. V.; Schammel, A. W.; Gevorgyan, V. Multisubstituted $\mathrm{N}$-fused heterocycles via transition metal-catalyzed cycloisomerization protocols. Tetrahedron 2008, 64, 6876-6883.

(69) Liu, R.-R.; Ye, S.-C.; Lu, C.-J.; Xiang, B.; Gao, J.; Jia, Y.-X. Aucatalyzed ring-opening reactions of 2-(1-alkynyl-cyclopropyl)pyridines with nucleophiles. Org. Biomol. Chem. 2015, 13, 4855-4858.

(70) Li, X.; Xie, X.; Liu, Y. Gold(I)-Catalyzed Cascade Hydroarylation/Cycloaromatization to Indolizines via Pyridine Ring Construction. J. Org. Chem. 2016, 81, 3688-3699.

(71) Crespo, O.; Gimeno, M. C.; Laguna, A.; Montanel-Pérez, S.; Villacampa, M. D. Facile Synthesis of Gold(III) Aryl-Carbene Metallacycles. Organometallics 2012, 31, 5520-5526.

(72) Li, Y.; Chen, X.; Song, Y.; Fang, L.; Zou, G. Well-defined Nheterocyclic carbene silver halides of 1-cyclohexyl-3-arylmethylimidazolylidenes: synthesis, structure and catalysis in $\mathrm{A}^{3}$-reaction of aldehydes, amines and alkynes. Dalton Trans. 2011, 40, 2046-2052.

(73) Choi, J.; Lim, J.; Irudayanathan, F. M.; Kim, H.-S.; Park, J.; Yu, S. B.; Jang, Y.; Raja, G. C. E.; Nam, K. C.; Kim, J.; Lee, S. CopperCatalyzed Double Decarboxylative Coupling Reactions of Alkynyl Carboxylic Acid and Glyoxylic Acid: Synthesis of Propargyl Amines and Imidazopyridines. Asian J. Org. Chem. 2016, 5, 770-777.

(74) Mishra, S.; Bagdi, A. K.; Ghosh, M.; Sinha, S.; Hajra, A. Zinc iodide: a mild and efficient catalyst for one-pot synthesis of aminoindolizines via sequential $\mathrm{A}^{3}$ coupling/cycloisomerization. RSC Adv. 2014, 4, 6672-6676.

(75) Obst, M.; Srivastava, A.; Baskaran, S.; König, B. Preparation of Propargyl Amines in a $\mathrm{ZnCl}_{2}$-Dimethylurea Deep-Eutectic Solvent. Synlett 2018, 29, 185-188.

(76) Sakaguchi, S.; Mizuta, T.; Furuwan, M.; Kubo, T.; Ishii, Y. Iridium-catalyzed coupling of simple primary or secondary amines, aldehydes and trimethylsilylacetylene: preparation of propargylic amines. Chem. Commun. 2004, 1638-1639. 
(77) White-Morris, R. L.; Olmstead, M. M.; Balch, A. L.; Elbjeirami, O.; Omary, M. A. Orange Luminescence and Structural Properties of Three Isostructural Halocyclohexylisonitrilegold(I) Complexes. Inorg. Chem. 2003, 42, 6741-6748.

(78) McCleverty, J. A.; da Mota, M. M. M. Isocyanide and carbene complexes of gold(I). The stepwise formation of formamidines. $J$. Chem. Soc., Dalton Trans. 1973, 2571-2574.

(79) Hashmi, A. S. K.; Yu, Y.; Rominger, F. Efficient One-Pot Synthesis of Unsymmetrical Gold(I) N-Heterocyclic Carbene Complexes and Their Use as Catalysts. Organometallics 2012, 31, 895-904.

(80) Leadbeater, N. E.; Torenius, H. M.; Tye, H. Microwave-assisted Mannich-type three-component reactions. Mol. Diversity 2003, 7, $135-144$.

(81) Shi, L.; Tu, Y.-Q.; Wang, M.; Zhang, F.-M.; Fan, C.-A. Microwave-Promoted Three-Component Coupling of Aldehyde, Alkyne, and Amine via $\mathrm{C}-\mathrm{H}$ Activation Catalyzed by Copper in Water. Org. Lett. 2004, 6, 1001-1003.

(82) Mitamura, T.; Ogawa, A. Copper(0)-Induced Deselenative Insertion of $N, N$-Disubstituted Selenoamides into Acetylenic $\mathrm{C}-\mathrm{H}$ Bond Leading to Propargylamines. Org. Lett. 2009, 11, 2045-2048.

(83) Sun, R.; Liu, J.; Yang, S.; Chen, M.; Sun, N.; Chen, H.; Xie, X.; You, X.; Li, S.; Liu, Y. $\mathrm{Cp}_{2} \mathrm{TiCl}_{2}$-catalyzed cis-hydroalumination of propargylic amines with Red-Al: stereoselective synthesis of Zconfigured allylic amines. Chem. Commun. 2015, 51, 6426-6429.

(84) Buckley, B. R.; Khan, A. N.; Heaney, H. Mannich Reactions of Alkynes: Mechanistic Insights and the Role of Sub-Stoichiometric Amounts of Alkynylcopper(I) Compounds in the Catalytic Cycle. Chem.-Eur. J. 2012, 18, 3855-3858.

(85) Lin, Z.; Yu, D.; Zhang, Y. Propargylic amines constructed via copper-catalyzed three-component coupling of terminal alkynes, benzal halides and amines. Tetrahedron Lett. 2011, 52, 4967-4970.

(86) Layek, K.; Chakravarti, R.; Kantam, M. L.; Maheswaran, H.; Vinu, A. Nanocrystalline magnesium oxide stabilized gold nanoparticles: an advanced nanotechnology based recyclable heterogeneous catalyst platform for the one-pot synthesis of propargylamines. Green Chem. 2011, 13, 2878-2887.

(87) Zhao, Y.; Zhou, X.; Okamura, T.-A.; Chen, M.; Lu, Y.; Sun, W.Y.; Yu, J.-Q. Silver supramolecule catalyzed multicomponent reactions under mild conditions. Dalton Trans. 2012, 41, 5889-5896.

(88) Albaladejo, M. J.; Alonso, F.; Yus, M. Synthesis of Indolizines and Heterocyclic Chalcones Catalyzed by Supported Copper Nanoparticles. Chem.-Eur. J. 2013, 19, 5242-5245.

(89) Mishra, S.; Bagdi, A. K.; Ghosh, M.; Sinha, S.; Hajra, A. Zinc iodide: a mild and efficient catalyst for one-pot synthesis of aminoindolizines via sequential $\mathrm{A}^{3}$ coupling/cycloisomerization. RSC Adv. 2014, 4, 6672-6676.

(90) Albaladejo, M. J.; Alonso, F.; González-Soria, M. J. Synthetic and Mechanistic Studies on the Solvent-Dependent Copper-Catalyzed Formation of Indolizines and Chalcones. ACS Catal. 2015, 5, 34463456. 